\title{
BASELINE VIRAL LOAD - A PREDICTOR OF TREATMENT RESPONSE IN ADVANCED HEPATITIS C
}

\author{
Irina Ivanova ${ }^{1}$, Iskren Kotsev ${ }^{1}$, Maria Atanassova ${ }^{1}$, Antonia Atanassova ${ }^{1}$, \\ Bogomila Manevska ${ }^{2}$, Ivan Krasnaliev ${ }^{2}$, Trifon Chervenkov ${ }^{3}$, Svetoslav Balev ${ }^{3}$ \\ ${ }^{1}$ Clinic of Gastroenterology, ${ }^{2}$ Department of Pathology and ${ }^{3}$ Laboratory of Clinical \\ Immunology, St. Marina University Hospital of Varna
}

\begin{abstract}
PURPOSE: The stage of liver disease and genotype of hepatitis C virus (HCV) are well-defined predictors for therapeutic success in chronic hepatitis $\mathrm{C}$. This study aimed at assessing the prognostic role of baseline viral load for response to antiviral therapy in genotype 1 infected patients.

MATERIAL AND METHODS: The study covered a total of 163 patients with hepatitis C, 93 of them with absent, mild or septal fibrosis (F0-F2) and 70 cases with bridging fibrosis (F3) or cirrhosis (F4). Viral load (HCV RNA) was determined with a sensitive RT-PCR technique. A high baseline viraemia was defined if HCV RNA exceeded $600000 \mathrm{IU} / \mathrm{mL}$. All the patients were treated with peginterferon alfa and ribavirin for 24 to 48 weeks. They achieved a sustained viral response (SVR) if HCV RNA was undetectable six month after therapy cessation.

RESULTS: SVR was registered in 80,6\% of the patients with F0-F2 fibrosis stage, in 51,4\% of those with F3F4 fibrosis and in only $25 \%$ of 12 patients with 'early' Child B cirrhosis or with present esophageal varices. Baseline viral load was not a prognostic factor for therapeutic effectiveness in early hepatitis $\mathrm{C}$ stage. However, in the advanced fibrosis stage, patients who achieved viral eradication had a significantly lower level of HCV RNA $(440000 \mathrm{IU} / \mathrm{mL})$ then those with relapse or non-response to therapy $(997000 \mathrm{IU} / \mathrm{mL})$.

CONCLUSION: The most 'difficult-to-treat' patients with HCV genotype 1 and advanced liver disease may successfully receive a standard treatment. The SVR rate is $51,4 \%$, reaching the results of current 'triple' therapy for F3-F4 stage. The viral eradication is associated with a low baseline viral load.
\end{abstract}

Key words: hepatitis $C$, cirrhosis, antiviral treatment, prognostic factors, viral load

\section{INTRODUCTION}

Until recent approval of the first direct-acting antivirals against hepatitis $\mathrm{C}$ virus (HCV), the combination of pegylated interferon and ribavirin was the standard therapy for chronic hepatitis C. Treat-

Address for correspondence:

Irina Ivanova, $M D, P h D$

Clinic of Gastroenterology,

St. Marina University Hospital

1 Hristo Smirnenski Str., 9010, Varna Bulgaria

e-mail:irinaiivanova@abv.bg

Received: July 2, 2013

Accepted: July 21, 2013 ment achieves a sustained viral response (SVR) related to cure of disease in $41 \%$ to $56 \%$ of the patients infected with HCV genotype 1 (7). This genotype prevails in Bulgaria (in $\sim 85-87 \%$ of the population). However, it is also known as a 'difficult-totreat' genotype. Among HCV genotype 1 patients' population, SVR rate depends on diverse factors, as cirrhosis presence plays the most important predictive role for treatment failure $(5-7,9,11)$. Recent studies identify the genetic polymorphism in interleukin $28 \mathrm{~b}$ (IL28B) gene as a strong factor for spontaneous and interferon-induced viral clearance (14). Other considered predictors for suboptimal viral eradication are: high baseline viral load; previous therapeu- 
tic failure; patient's age > 40 years; male gender; body weight $>75 \mathrm{~kg}$ or obesity; insulin resistance; concomitant steatosi; elevated GGT level; high ferritin level; patient's low motivation and non-adherence to therapy as well as cumulative exposure to interferon and ribavirin and grade of hemoglobin reduction $(4,6,10,12)$. Given the interferon-ribavirin treatment side-effects and healthcare costs, identifying the patients who are less probable 'responders' is highly desirable. Some patients with unfavourable baseline characteristics could become appropriate candidates for new 'triple' treatment regimens, including direct acting antiviral drugs.

The present study was designed to analyze baseline characteristics associated with SVR in most 'difficult-to-treat' genotype 1 patients with chronic hepatitis $\mathrm{C}$ at stage of advanced fibrosis and cirrhosis.

\section{MATERIAL AND METHODS}

This observational trial included 163 patients diagnosed with chronic hepatitis $\mathrm{C}$ and treated in our referral center with peginterferon-alpha plus ribavirin under routine clinical practice conditions from 2004 to 2011. The target group consisted of 70 patients with advanced hepatitis C: of them, 35 presented with advanced fibrosis (F3) and 35 with cirrhosis (F4). Data from treatment results were collected from our medical records and were compared to therapy response of 93 consecutive patients with early stage of disease (F0-F2 fibrosis stages, according to METAVIR). All the patients were registered as infected with HCV genotype 1 at baseline. Serum HCV RNA levels were evaluated at baseline, at week 12 and at the end of follow-up. Measurements were done using quantitative real-time polymerase chain reaction Taqman assay (Amplisence, CRIE) with a lower limit of detection of $5 \mathrm{IU} / \mathrm{mL}$. HCV RNA level higher than $600000 \mathrm{IU} / \mathrm{mL}$ was defined as high viral load. Stage of disease was assessed by liver biopsy according to Menghini technique. Fibrosis was examined by experienced pathologist using METAVIR scoring system (as score F0 to F4). Only five patients were invasively staged as cirrhotic based on firm liver, ultrasound and endoscopic data for portal hypertension. As the patients with advanced liver disease were eventually heterogeneous population, they were divided into three groups such as: bridging fibrosis ( $\mathrm{F} 3, \mathrm{n}=35)$; fully compensated 'histological' cirrhosis (F4 with normal liver synthetic function, absence of esophageal varices and thrombocyte level $>125 \times 10^{9} / 1,(n=23)$; cirrhosis and clinically significant portal hypertension - esophageal varices, splenomegaly with hypersplenism and/or disturbed liver function assessed with Child-Pough score 6 or $7(n=12)$. Therapy was administered per protocol of our current National Consensus on treatment of chronic viral hepatitis in adult patients. Pegylated interferon alpha-2a (180 mcg s. c. per week) was given in addition with oral ribavirin (1000-1200 mg per day according to body weight)) for 24 weeks in patients without early virologic response (EVR) and for 48 weeks for patients who had achieved EVR. Then the patients were followed-up for at least 24 weeks after therapy completion and SVR was registered if $\mathrm{HCV}$ RNA remained negative at the end of following-up. The following variables were recorded at the start of treatment: patient's age; gender; weight registered as three categories (normal, overweight and obesity); liver enzymes activity (ALT, AST, and GGT); viremia level (HCV RNA) and histological activity (defined as mild, moderate and severe). Bivariate analysis was carried out using Mann-Whitney's $t$ test for quantitative variables and the chi-square test as well as one-way ANOVA for the remaining qualitative variables. The statistical analysis was performed by means of a free version of GraphPad Prism 6.0 statistical software.

\section{RESULTS}

Demographic data, clinical, laboratory and morphological findings in the target group of patients with advanced hepatitis $\mathrm{C}$ were summarized in Table 1.

The mean age of the patients with bridging fibrosis was $47 \pm 13$ years as compared to age of the patients with cirrhosis ( $56 \pm 9$ years). There was no statistical difference in baseline viral load (Fig. 1), transaminase levels and histological activity between the patients with advanced liver disease. A high baseline viral load was established in 38,6\% of F3-F4 patients have.

There was a very high prevalence of diabetes mellitus in F3-F4 patients (in 45\%), as most cases 
Irina Ivanova, Iskren Kotsev, Maria Atanassova et al.

Table 1: Baseline characteristics of patients with advanced liver disease $(n=70)$

\begin{tabular}{|c|c|c|}
\hline Parameter & $\mathrm{n}$ & range / \% \\
\hline male/female ratio & \multicolumn{2}{|c|}{$33 / 37$} \\
\hline mean age at diagnosis (years) & 51,4 & $23-69$ \\
\hline \multicolumn{3}{|l|}{ route of transmission } \\
\hline - transfusion of blood / blood products & 25 & 35,7 \\
\hline - intravenous drug use & 3 & 4,3 \\
\hline - unknown & 19 & 27,1 \\
\hline documentation for previous acute $\mathrm{C}$ (non-A, non-B) hepatitis & 11 & 15,7 \\
\hline mean duration of infection (years) & 24 & $10-42$ \\
\hline daily alcohol consumption $>50 \mathrm{~mL}$ & 12 & 17,1 \\
\hline prevalence of overweight and obesity $(\mathrm{BMI} \geq 25)$ & 28 & 40 \\
\hline prevalence of diabetes mellitus & 32 & 45,7 \\
\hline prevalence of symptoms of liver disease & 48 & 68,6 \\
\hline \multicolumn{3}{|l|}{ Child-Pough score (in cirrhosis, $\mathrm{n}=35$ ) } \\
\hline-5 & 27 & 77 \\
\hline-6 & 5 & 14 \\
\hline-7 & 3 & 9 \\
\hline platelets count $\left(\mathrm{x} 10^{9} / \mathrm{L}\right)$ & 164 & $85-320$ \\
\hline mean ALT (U/L) & 119 & $29-320$ \\
\hline AST/ALT ratio & \multicolumn{2}{|c|}{0,86} \\
\hline predominant GGT elevation & 16 & 22,8 \\
\hline cholestasis (alkaline phosphatase) & 4 & 5,7 \\
\hline high baseline viremia (>600000 IU/mL) & 27 & 38,6 \\
\hline \multicolumn{3}{|l|}{ grade of histological activity $(n=65)$} \\
\hline - mild & 13 & 20 \\
\hline - moderate & 40 & 61,5 \\
\hline - severe & 12 & 18,5 \\
\hline \multicolumn{3}{|l|}{ grade of steatosis } \\
\hline - absent & 35 & 50 \\
\hline - mild & 24 & 34,2 \\
\hline - moderate & 7 & 10 \\
\hline - severe & 4 & 5,7 \\
\hline
\end{tabular}

were well-controlled on a diet. Prevalence of diabetes mellitus in F0-F2 patients of 2,5\% reflected approximately the rates reported in the general population. Mean baseline platelet count was $164 \times 10^{9} / \mathrm{L}$ (between 85 and $320 \times 10^{9} / \mathrm{L}$ ). Besides, mean AST/ALT ratio was 0,86 emphasizing that the finding of AST/ALT $>0,8$ in screened patients might be a feature directed to the presence of advanced liver disease.

Treatment was successful in 36 patients with advanced liver disease and established SVR rate of $51,4 \%$ was significantly lower than excellent treatment response in $80,6 \%$ of the patients with F0-F2 fibrosis stage. Relapse and non-response rates in F3-F4 patients were equal - 24,3\%. Viral eradication rates were $60 \%$ in $\mathrm{F} 3$ patients, $55 \%$ in patients with 'histological' cirrhosis and only $25 \%$ in 12 treated patients with portal hypertension and/or early liver synthetic dysfunction (Fig. 2).

We did not establish any significant association with SVR and the following baseline characteristics: age, gender, weight, biochemical and histological activity between the treated patients with advanced liver disease. High viral load was not associated with therapeutic failure within F0-F2-staged hepatitis $\mathrm{C}$ patients. In contrast, F3-F4 patients that had achieved SVR presented with a statistically significantly lower baseline HCV RNA level (mean level 


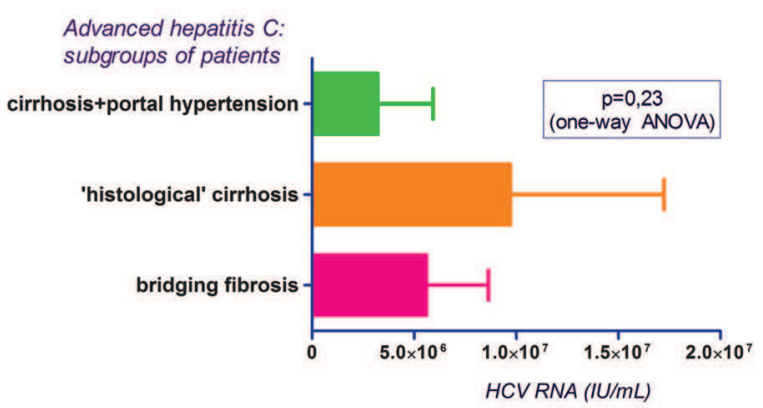

Fig. 1. Baseline HCV RNA level in patients with advanced liver disease

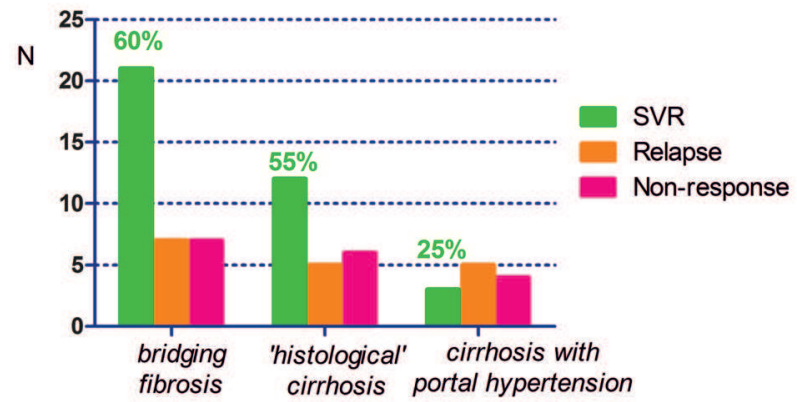

Fig. 2. Therapeutic results in patients with advanced liver disease

of $440000 \mathrm{IU} / \mathrm{mL}$ ) than 'relapsers' and non-responders to interferon-ribavirin therapy (mean level of 997000 IU/mL) (Fig. 3).

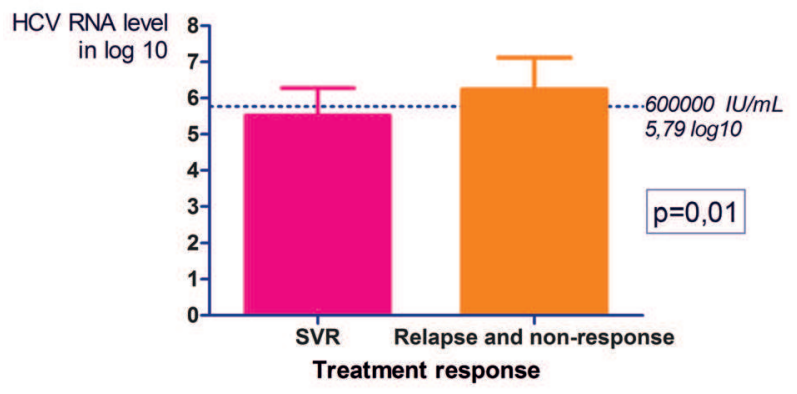

Fig. 3. Baseline viral load in patients with advanced liver disease according to treatment response

In addition, SVR rate in the subgroup of patients with low viral load was $65 \%$ as compared to $30 \%$ among the patients with high initial level of HCV RNA (for this analysis set to above 600000 IU/ $\mathrm{mL}$ ). The difference between these proportions was highly statistically significant.

\section{DISCUSSION}

The response to standard 'bi-therapy' with peginterferon and ribavirin is heterogeneous and is proved as suboptimal in hepatitis $\mathrm{C}$ patients infected with genotype 1 and those with advanced fibrosis $(2,3,8)$. In order to investigate certain other important baseline factors associated with SVR we performed this retrospective analysis focused on series of genotype 1 patients with advanced liver disease treated under routine clinical conditions. We found out that $51,4 \%$ of 'naive' patients with advanced fibrosis and cirrhosis achieved SVR. This response rate was comparable or even higher than that reported in international trials with peginterferon-alpha plus ribavirin reaching results with a current 'triple' combination therapy for stage F3-F4 (1).

Baseline HCV viral load is an independent predictive factor of treatment response in pivotal studies $(9,11,13,15)$. However, other analyses in clinical settings do not confirm the assumption that viral load constitutes a predictive factor for treatment response (5). The successfully treated patients of ours are those who demonstrate a lower baseline viral load. Initial HCV RNA level is the only baseline factor associated with SVR in this patients' population that challenges for treatment. We have not performed any multiple logistic regression analysis in the present smallgroup study and this circumstance could be considered a methodological disadvantage. However, in our modest opinion, well-registered experience can be helpful in clinical decision making.

\section{CONCLUSION}

The most 'difficult-to-treat' patients with HCV genotype 1 and advanced liver disease may successfully receive a standard treatment with SVR rate of $51,4 \%$, reaching the results of current 'triple' therapy for F3 and F4 stages. The viral eradication is associated with a low baseline viral load. According to our study, 'naive' HCV genotype 1 patients with baseline high viral load, portal hypertension and/or early liver synthetic dysfunction urgently necessitate triple combination therapy because of low chance of response to standard treatment.

\section{REFERENCES}

1. Bourlière, M., A. Khaloun, C. Wartelle-Bladou, V. Oules, I. Portal, S. Benali, et al. Future treatment of 
Irina Ivanova, Iskren Kotsev, Maria Atanassova et al.

patients with HCV cirrhosis.- Liver Int., 32, 2012, Suppl. 1, 113-119.

2. Cheng, W. S., S. K. Roberts, G. McCaughan, W. Sievert, M. Weltman, D. Crawford, et al.; CHARIOT Study Group. Low virological response and high relapse rates in hepatitis $\mathrm{C}$ genotype 1 patients with advanced fibrosis despite adequate therapeutic dosing.- J. Hepatol., 53, 2010, No 4, 616-623.

3. Di Marco, V., P. L. Almasio, D. Ferraro, V. Calvaruso, G. Alaimo, S. Peralta, et al. Peginterferon alone or combined with ribavirin in $\mathrm{HCV}$ cirrhosis with portal hypertension: a randomized controlled trial.- J. Hepatol., 47, 2007, No 4, 484-491.

4. Ferenci, P. Predicting the therapeutic response in patients with chronic hepatitis C: the role of viral kinetic studies.- J. Antimicrob. Chemother., 53, 2004, No 1, 15-18.

5. García-Samaniego, I., M. Romero, R. Granados, R. Alemán, M. Jorge Juan, D. Suárez,_et al. Factors associated with early virological response to peginterferon- $\alpha-2 a /$ ribavirin in chronic hepatitis C.- World J. Gastroenterol., 19, 2013, No 12, 1943-1952.

6. Gheorghe, L., S. Iacob, I. Sporea, M. Grigorescu, R. Sirli, D. Damian, et al. Efficacy, tolerability and predictive factors for early and sustained virologic response in patients treated with weight-based dosing regimen of PegIFN alpha-2b ribavirin in real-life healthcare setting.- J. Gastrointestin. Liver Dis., 16, 2007, No 1, 23-29.

7. Hadziyannis, S. J., J. H. Sette, T. R. Morgan, V. Balan, M. Diago, P. Marcellin, et al.; PEGASYS International Study Group. Peginterferon-alpha2a and ribavirin combination therapy in chronic hepatitis $\mathrm{C}$ : a randomized study of treatment duration and ribavirin dose.- Ann. Intern. Med., 140, 2004, No 5, 346-355.

8. Helbling, B., W. Jochum, I. Stamenic, M. Knöpfli, A. Cerny, J. Borovicka, et al.; Swiss Association for the Study of the Liver (SASL). HCV-related advanced fibrosis/cirrhosis: randomized controlled trial of pegylated interferon alpha-2a and ribavirin.- J. Viral Hepat., 13, 2006, No 11, 762-769.
9. Jensen, D. M., T. R. Morgan, P. Marcellin, P. J. Pockros, K. R. Reddy, S. J. Hadziyannis, et al. Early identification of HCV genotype 1 patients responding to 24 weeks peginterferon alpha-2a (40 kd)/ribavirin therapy.- Hepatology, 43, 2006, No 5, 954-960.

10. Lindsay, K. L., C. Morishima, E. C. Wright, J. L. Dienstag, M. L. Shiffman, G. T. Everson, et al.; HALT-C Trial. Blunted cytopenias and weight loss: new correlates of virologic null response to re-treatment of chronic hepatitis C.- Clin. Gastroenterol. Hepatol., 6, 2008, No 2, 234-241.

11. Mangia, A., N. Minerva, D. Bacca, R. Cozzolongo, G. L. Ricci, V. Carretta, et al. Individualized treatment duration for hepatitis $\mathrm{C}$ genotype 1 patients: a randomized controlled trial.Hepatology, 47, 2008, No 1, 43-50.

12. Reddy, K. R., D. Messinger, M. Popescu, S. J. Hadziyannis. Peginterferon alpha-2a (40 kDa) and ribavirin: comparable rates of sustained virologicaln response in sub-sets of older and younger HCV genotype 1 patients.- J. Viral Hepat., 16, 2009, No 10, 724-731.

13. Rodriguez-Torres, M., M. S. Sulkowski, R. Chung, F. M. Hamzeh, D. M. Jensen. Factors associated with rapid and early virologic response to peginterferon alfa-2a/ribavirin treatment in $\mathrm{HCV}$ genotype 1 patients representative of the general chronic hepatitis C population.- J. Viral Hepat., 17, 2010, No 2, 139-147.

14. Thompson, A. J., A. J. Muir, M. S. Sulkowski, D. Ge, J. Fellay, K. V. Shianna, et al. Interleukin$28 \mathrm{~B}$ polymorphism improves viral kinetics and is the strongest pretreatment predictor of sustained virologic response in genotype 1 hepatitis $\mathrm{C}$ virus.Gastroenterology, 139, 2010, No 1, 120-129.

15. Yu, M. L., C. Y. Dai, J. F. Huang, C. F. Chiu, Y. H. Yang, N. J. Hou, et al. Rapid virological response and treatment duration for chronic hepatitis C genotype 1 patients: a randomized trial.Hepatology, 47, 2008, No 6, 1884-1893. 